\title{
Study on UV Opto-Electric Properties of ZnS:Mn/ZnS Core-Shell QD
}

\author{
Yun-Ji Lee, Ji-Min Cha, Chang-Bun Yoon, and Seong-Eui Lee ${ }^{\dagger}$ \\ Department of Advanced Material, Korea Polytechnic University, Si-heung 15073, Korea \\ (Received November 2, 2017; Revised December 11, 2017; Accepted December 11, 2017)
}

\begin{abstract}
In this study, quantum dots composed of $\mathrm{Mn}^{2+}$ doped $\mathrm{ZnS}$ core and $\mathrm{ZnS}$ shell were synthesized using MPA precursor at room temperature. The $\mathrm{ZnS}: \mathrm{Mn} / \mathrm{ZnS}$ quantum dots were prepared by varying the content of MPA in the synthesis of ZnS shells. XRD, Photo-Luminescence (PL), XPS and TEM were used to characterize the properties of the $\mathrm{ZnS}$ : Mn/ZnS quantum dots. As a result of PL measurement using UV excitation light at $365 \mathrm{~nm}$, the PL intensity was found to greatly increase when MPA was added at $15 \mathrm{ml}$, compared to the case with no MPA; the PL peaks shifted from $603 \mathrm{~nm}$ to $598 \mathrm{~nm}$. A UV sensor was fabricated by using a sputtering process to form a Pt pattern and placing a QD on the Pt pattern. To verify the characteristics of the sensor, we measured the electrical properties via irradiation with UV, Red, Green, and Blue light. As a result, there were no reactions for the R, $\mathrm{G}$, and B light, but an energy of $3.39 \mathrm{eV}$ was produced with UV light irradiation. For the sensor using $\mathrm{ZnS}: \mathrm{Mn} / \mathrm{ZnS}$ quantum dots, the maximum current $(\mathrm{A})$ value decreased from $4.00 \times 10^{-11} \mathrm{~A}$ to $2.62 \times 10^{-12} \mathrm{~A}$ with increasing of the MPA content. As the MPA content increases, the PL intensity improves but the electrical current value dropped because of the electron confinement effect of the core-shell.
\end{abstract}

Key words : ZnS:Mn ${ }^{2+}$ Quantum Dot (QD), Photoconductive sensor, Core-Shell, Ultraviolet

\section{Introduction}

$\mathbf{R}$ esearch on optical sensors utilizing nanomaterials has been actively conducted for numerous years; such optical sensors have been in the spotlight for their performance and efficiency. Also, various studies are being carried out on quantum dot technology, which uses size control to produce high quantum efficiency and convenient reproduction of a wide range of colors. Among such studies, research on photoconductive sensors has utilized conventional commercialized $\mathrm{Cd}$ and $\mathrm{Pb}$, but these materials have problems including ingredient toxicity, high temperature process for synthesis, hazardous source materials, and high cost materials. Thus, $\mathrm{ZnS}$ quantum dots are in the process of commercialization because they are expected to adequately realize the role of photoconductive sensor due to their large band gap and stability under high currents. However, conventional $\mathrm{Zn}$ quantum dots require complex manufacturing processes and various types of equipment. Therefore, in this study, the room temperature solution method was applied to conveniently synthesize an $\mathrm{ZnS}: \mathrm{Mn}^{2+}$ core and to establish a shell using $\mathrm{ZnS}$. MPA was used as the precursor; the $\mathrm{ZnS}: \mathrm{Mn} / \mathrm{ZnS}$ quantum dot properties were observed according to the MPA content.

Moreover, photoconductive sensors of PN junction type and Schottky type were fabricated; the PN junction type sensor has the disadvantage of a complex fabrication pro-

\footnotetext{
${ }^{\dagger}$ Corresponding author : Seong-Eui Lee

E-mail : selee@kpu.ac.kr

Tel : +82-31-8041-0588 Fax : +82-31-8041-0599
}

cess. On the other hand, compared to the PN junction type, the Schottky type allows for higher frequency usage and has a relatively simple fabrication process. Therefore, in this study, these characteristics were considered in the fabrication of a Schottky type quantum dot based photoconductive sensor; its performance as a sensor was investigated, as were the effects on the sensor of $\mathrm{ZnS}: \mathrm{Mn} / \mathrm{ZnS}$ quantum dots with various MPA content. ${ }^{1-6)}$

\section{Experimental Procedure}

\subsection{ZnS:Mn ${ }^{2+}$ Quantum Dot Fabrication}

In this study, the wet reduction method, a type of chemical synthesis method, was used to synthesize $\mathrm{ZnS}: \mathrm{Mn}^{2+}$ $\mathrm{ZnS}: \mathrm{Mn} / \mathrm{ZnS}$ quantum dots. First, the ZnS:Mn core was fabricated. $\mathrm{Zn}\left(\mathrm{CH}_{3} \mathrm{COO}\right)_{2} \cdot 2 \mathrm{H}_{2} \mathrm{O}$ (JUNSEI) and $\mathrm{Mn}\left(\mathrm{CH}_{3} \mathrm{COO}\right)_{2} \cdot 4 \mathrm{H}_{2} \mathrm{O}$ (DAEJUNG) were each dissolved in D.I water for approximately 10 minutes to prepare the aqueous solution. A specific amount of $\mathrm{Na}_{2} \mathrm{~S}$ (ALDRICH) was added to the fabricated solution to form the $\mathrm{ZnS}: \mathrm{Mn}^{2+}$ complex compound. Afterwards, the shell was formed. The fabricated $\mathrm{ZnS}: \mathrm{Mn}$ core was dissolved in $200 \mathrm{ml}$ of D.I water (see Fig. 1). For ZnS shell formation, after adding $\mathrm{Zn}\left(\mathrm{CH}_{3} \mathrm{COO}\right)_{2} \cdot 2 \mathrm{H}_{2} \mathrm{O}$ at a ratio of 0.1 relative to the core to the dissolved $\mathrm{ZnS}: \mathrm{Mn}^{2+}$ core solution, MPA (3-Mercaptopropionic acid) was added in varying amounts. Then, after adding $\mathrm{Na}_{2} \mathrm{~S}$, the solution was dissolved for around 30 minutes at $200 \mathrm{rpm}$; this was followed by analysis of the final compound. In the case of MPA, the precursor formed, affecting the shell formation; the influence of the MPA content variation on the shell formation was analyzed. ${ }^{7-10)}$ 


\section{Experiment}

\begin{tabular}{|c|}
\hline $\mathrm{Zn}\left(\mathrm{CH}_{3} \mathrm{COO}\right)_{2} \cdot 2 \mathrm{H}_{2} \mathrm{O}-4.932 \mathrm{~g}$ \\
D.I Water $10 \mathrm{ml}$ \\
10 min stirring \\
\hline $\mathrm{Mn}\left(\mathrm{CH}_{3} \mathrm{COO}\right)_{2} \cdot 4 \mathrm{H}_{2} \mathrm{O}-0.27 \mathrm{~g}$ \\
D.I Water $10 \mathrm{ml}$ \\
10 min stirring \\
\hline $\mathrm{NaS}-1.404 \mathrm{~g}$ \\
$10 \mathrm{~min}$ stirring \\
\hline 20 min stirring $(200 \mathrm{rpm})$ \\
\hline
\end{tabular}

Fig. 1. ZnS:Mn Core Process.

XRD (Rigaku d-max/2200) was used to observe the synthesis and crystallinity of the final synthesized materials; PL Spectrum (FS-2) was measured to investigate the photoluminescence properties according to the MPA content. Also, the binding energy and band gap between the constitutive elements during the shell formation for each material were measured using XPS (PHI 5000 Versa Probe. UlvacPHI). TEM (FEI Co. Tecnai G2 F20) was used to investigate the particle size of the synthesized solution and the shell formation.

\section{2. $\mathrm{ZnS}: \mathrm{Mn}^{2+} \mathrm{UV}$ Sensor Fabrication}

For the UV sensor fabrication, lift-off photolithography with DFR (Dry Film Resist) applied on glass was used to form the Pt/Ti electrode pattern, with an electrode width of $100 \mathrm{um}$ and a gap spacing of $100 \mathrm{um}$, as shown in Fig. 2. Afterwards, QDs with various MPA contents including $0 \mathrm{ml}$, $5 \mathrm{ml}, 10 \mathrm{ml}$, and $15 \mathrm{ml}$ in the $\mathrm{ZnS}: \mathrm{Mn}$ core and $\mathrm{ZnS}: \mathrm{Mn} / \mathrm{ZnS}$ were applied. For the lift-off DFR pattern, an exposure amount of $180 \mathrm{~mJ}$ and development time of $4.7 \mathrm{~min}$ were used. For the electrode formation, considering the $\mathrm{ZnS}: \mathrm{Mn} /$ ZnS QD properties, Pt was used because Pt exhibits low reactivity, does not react with nitric or sulfuric acid, and does not oxidize when exposed to oxygen. However, Pt has poor adhesion with glass, so the electrode was formed by deposition of Pt to a thickness of $100 \AA$ after deposition of Ti to a thickness of $500 \AA$. Sputtering (DC magnetron sputter system) was used for Ti deposition at $200 \mathrm{~W}, 10$ mtorr, and $6 \mathrm{sccm}$ of Ar gas for approximately $10 \mathrm{~min}$; this was followed by $\mathrm{Pt}$ deposition at $0.15 \mathrm{~A}, 10 \mathrm{mtorr}$, and $10 \mathrm{sccm}$ of Ar gas for approximately 20 minutes. ${ }^{11-13)}$

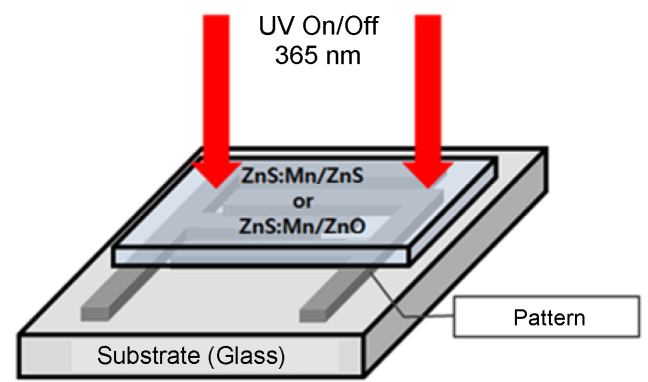

Fig. 2. Photoconductive Sensor manufactured using Quantum Dots.
The ZnS:Mn core, fabricated after the electrode formation, and the ZnS:Mn/ZnS QDs of various MPA content were applied to top of the glass. The solution was applied at regular amounts between $0.5 \mathrm{ml} \sim 1 \mathrm{ml}$ using a disposable pipette. After applying the solution, it was dried at room temperature and in a vacuum of $10^{-3}$ torr to prevent any impurities.

Since the fabricated sensor was supposed to react only with UV (365 nm), it was irradiated with Red (600 650 $\mathrm{nm}$ ), Green (500 $530 \mathrm{~nm}$ ), Blue (450 nm), and UV (365 $\mathrm{nm}$ ). A probe station (current probe) manufactured by TECH, which measured the current variation per material, was used to examine the potential of this device as a UV sensor.

\section{Results and Discussion}

\subsection{XRD and TEM Analyses According to the MPA Content}

In order to investigate the phase change of the QD for each material according to the MPA content, which acts as the precursor, and according to the capping acid during QD formation, D/max-2200 XRD equipment manufactured by Rigaku was used to measure and analyze the X-ray diffraction pattern.

The liquid phase ZnS:Mn core and ZnS:Mn/Zns QDs were measured by using a pipette to drop approximately $1 \mathrm{ml}$ samples of each on slide glasses and drying those samples at room temperature in a vacuum environment for $24 \mathrm{~h}$.

In Fig. 3, the formation of a stable cubic structure of the synthesized ZnS:Mn core can be observed through the XRD diffraction pattern. As the MPA content increased, an

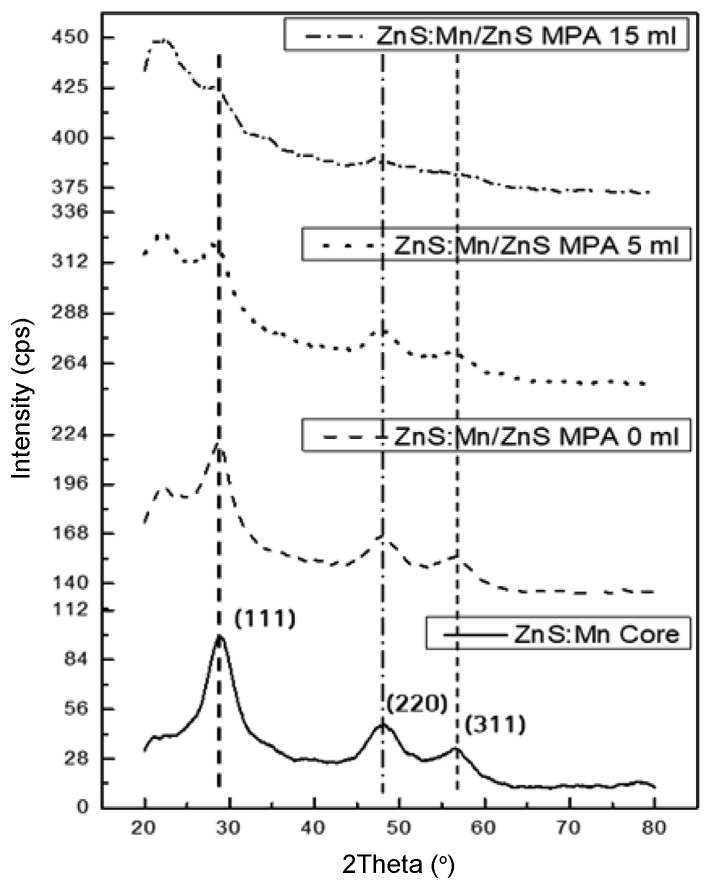

Fig. 3. XRD diffraction pattern of the $\mathrm{ZnS}: \mathrm{Mn} / \mathrm{ZnS}$. 


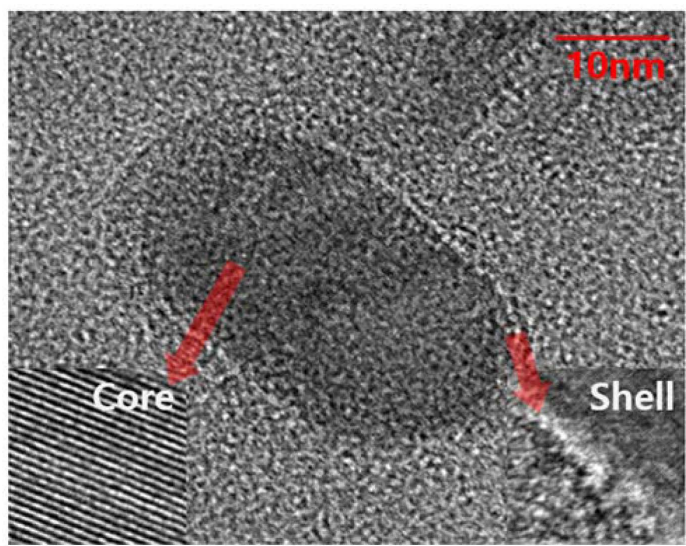

Fig. 4. TEM image of $\mathrm{ZnS}: \mathrm{Mn} / \mathrm{ZnS}$.

increasing trend of the half-width of the $\mathrm{ZnS}$ shell peak was observed; this was due to the effect of increasing defects on the surface. It was thought that the half-width increased because of the failure to completely prevent the occurrence of defects on the MPA surface and the exhibition of amorphous characteristics of the MPA itself.

In order to determine the presence of shell formation for the fabricated QDs, TEM (Transmission Electron Microscopy) was conducted using the Tecnai G2 F20 model manufactured by FEI. For the TEM samples, particles were dispersed in D.I. water for 3 min using ultrasound; particles were then applied to a grid. Then, hot air drying was conducted at $80^{\circ} \mathrm{C}$ before the analysis. Measurement results revealed that the $\mathrm{ZnS}: \mathrm{Mn} / \mathrm{ZnS}$ shell had one layer form on the outermost exterior. In Fig. 4, it can be observed that the particles were of spherical shape and that the cores of the particles had a lattice structure of $3 \AA$, matching the lattice structure of $\mathrm{ZnS}: \mathrm{Mn}$, with crystalline formation. However, the $\mathrm{ZnS}$ portion of the outermost layer, which appeared to be a shell, was amorphous and its lattice structure unclear. Through this, the formation of the $\mathrm{ZnS}: \mathrm{Mn}$ core-shell was observed.

\subsection{PL Property According to the MPA Content}

Photoluminescence (PL) variations of the core and synthesized QDs were measured to investigate the optical properties according to the MPA content during the $\mathrm{ZnS}: \mathrm{Mn}^{2+} \mathrm{ZnS}$ synthesis. The results were plotted and compared. The PL spectrum was measured using a quartz tube. According to the PL peak location on the graph shown in Fig. 5, it was determined that the $\mathrm{ZnS}: \mathrm{Mn}^{2+}$ core was emitting orange light at $603 \mathrm{~nm}$. In addition, absorption during the fabrication of $\mathrm{ZnS}: \mathrm{Mn} / \mathrm{ZnS}$ QDs was found to be between $290 \mathrm{~nm}$ to $300 \mathrm{~nm}$, as shown in Fig. 5(a); the absorption spectra did not show significant differences depending on the MPA content. On the other hand, the emission spectrum showed that the PL peak location shifted from $603 \mathrm{~nm}$ to $598 \mathrm{~nm}$ with increasing MPA content, as shown in Fig. 5(b); as the MPA content increased, the PL intensity also significantly increased relative to that of the $0 \mathrm{ml} \mathrm{MPA} \mathrm{ZnS}: \mathrm{Mn} / \mathrm{ZnS}$ sample. This
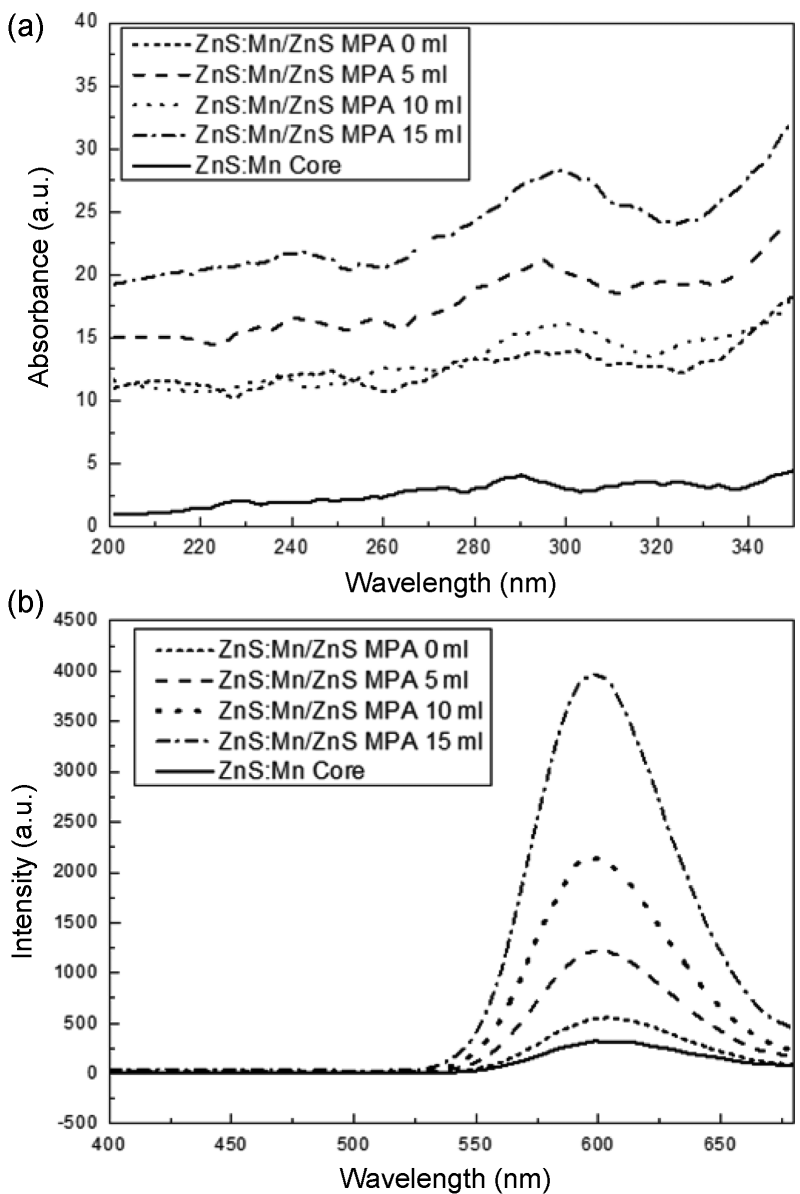

Fig. 5. PL properties of $\mathrm{ZnS}$ Shell according to MPA amount. (a) Absorption spectrum of $\mathrm{ZnS}: \mathrm{Mn} / \mathrm{ZnS}$, (b) Emission spectrum of $\mathrm{ZnS}: \mathrm{Mn} / \mathrm{ZnS}$.

result was due to the formation of a thiol ligand on the surface to facilitate the formation of the $\mathrm{ZnS}$ shell as more MPA is added to the $\mathrm{ZnS}: \mathrm{Mn}$ core. As a result, the core-shell structure formation became more stable as the MPA content increased.

The PL intensity increase and peak shift can be explained using the quantum effect, in which electron movement, which was unrestricted in the core, is no longer unrestricted beyond the shell. Electron movement was now limited to within the core because of the formation of the core-shell

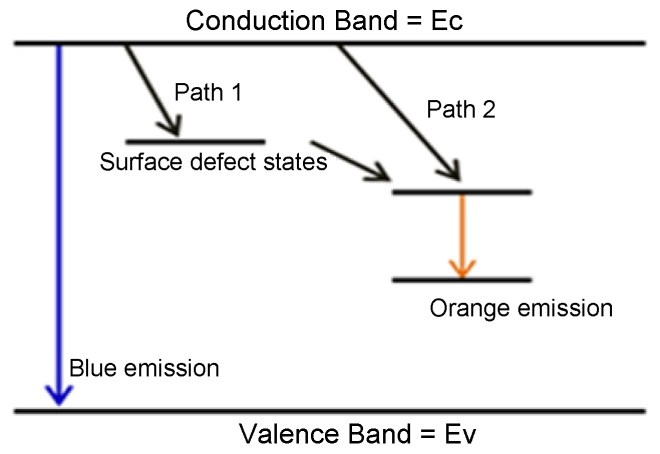

Fig. 6. Defect level in Band Gap. 
structure; this results in quantum efficiency and PL intensity increase due to increases in electron movement. Also, MPA acts as a precursor during the core-shell formation; however, unsaturated bonding at the surface could not be completely prevented, and this produced defects on the surface. Such defects form a defect level between the valence and conduction bands and induce a phenomenon in which excited electrons do not move to the doped $\mathrm{Mn}^{2+}$ level and emit but rather move to the above defect level and then become excited (see Fig. 6). In this manner, either a PL peak shift from $603 \mathrm{~nm}$ to $598 \mathrm{~nm}$ or a blueshift was observed. ${ }^{14)}$

\subsection{XPS Properties According to MPA Content}

Table 1 shows the measurement data, obtained using XPS to calculate the $\mathrm{Zn}$ bond loss energy, for the fabricated $\mathrm{ZnS}: \mathrm{Mn}^{2+} \mathrm{QD}$ band gap during the ZnS shell process. The calculated results show that as the MPA content relative to the core increased, the $\mathrm{ZnS}: \mathrm{Mn} / \mathrm{ZnS}$ QD band gap increased. ${ }^{15}$ The same conditions were used for the core; the varying parameter was the MPA content. As such, it was deduced that the calculated band gap reflected the shell characteristics. This result was related to the PL intensity measured earlier. The ZnS shell QDs had a type 1 structure (Fig. 7), in which the core band gap was smaller than the shell band gap. In this case, core electrons and holes are not lost to the outside; instead, the electrons and holes exist within the core and are simultaneously delocalized due to the peak shift and defects. ${ }^{16-18)}$ Therefore, electrons and holes exist within the same structure for type 1 structures, and this affects the PL intensity. Also, as the band gap increases, recombination of electrons and holes becomes easier, increasing the electron drought effect with regard to quantum efficiency. The probability of electron and hole recombination increases; this recombination causes the emission of

Table 1. Band Gap of Quantum Dots Manufactured Using Different MPA Amounts

\begin{tabular}{cc}
\hline ZnS:Mn/ZnS + MPA Content & Band Gap \\
\hline ZnS:Mn/ZnS Core & $3.5 \mathrm{eV}$ \\
ZnS:Mn/ZnS MPA 0 ml & $3.61 \mathrm{eV}$ \\
ZnS:Mn/ZnS MPA $5 \mathrm{ml}$ & $4.15 \mathrm{eV}$ \\
ZnS:Mn/ZnS MPA 15 ml & $4.3 \mathrm{eV}$ \\
\hline
\end{tabular}

Type I (ZnS:Mn/ZnS)

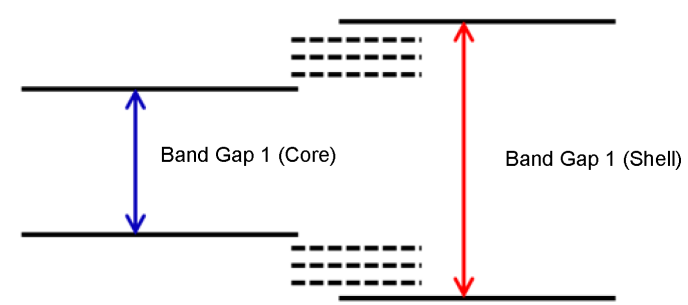

Fig. 7. ZnS:Mn/ZnS Quantum Dot structure.

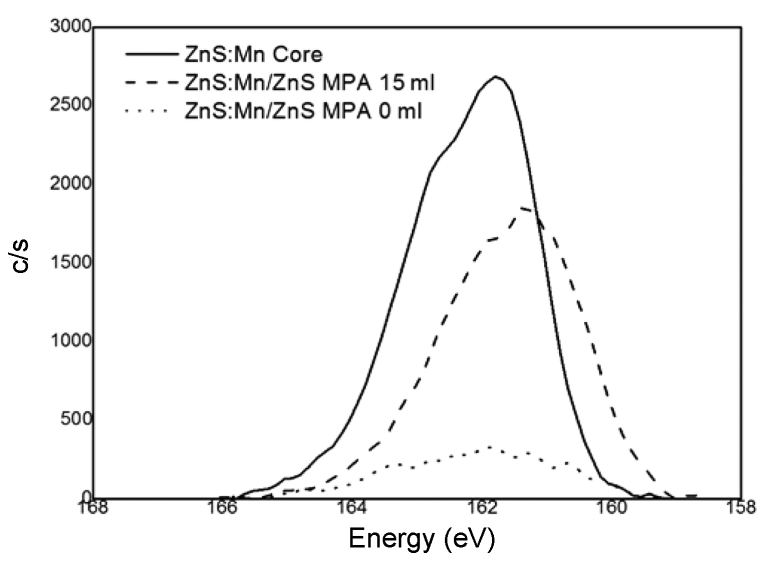

Fig. 8. Variation of S Binding Energy according to MPA content.

radiative and nonradiative energy, which in turn increases the PL intensity.

Figure 8 shows the $\mathrm{S}$ binding energy according to the MPA content; it can be seen that the $\mathrm{S}$ binding energy increased as the MPA content increased. This result was thought to be due to changes caused by the $\mathrm{ZnS}$ shell formation. Compared to the $\mathrm{S}$ binding energy for core formation, the $\mathrm{S}$ binding energy for the $15 \mathrm{ml} \mathrm{MPA} \mathrm{ZnS}: \mathrm{Mn} / \mathrm{ZnS}$ sample increased more than that for the 0ml MPA ZnS:Mn/ZnS; this result was due to the $\mathrm{ZnS}: \mathrm{Mn}$ bond in the case of the core. As the MPA content increases, the binding energy variation for the $\mathrm{ZnS}$ shell formation changes, and the above results show that the formation was stronger with increased MPA content. This result is related to the band gap calculations carried out using the $\mathrm{Zn}$ bond. Considering the results of both increased band gap and strengthened S binding energy as the MPA content increased, it can be said that the electron drought effect of the QD core-shell increased with increasing MPA content, resulting in increased PL intensity.

\subsection{UV Sensor R.G.B Test}

Figure 9 shows the response and the current amount of the fabricated sensor when Red $(600 \sim 650 \mathrm{~nm})$, Green (500 $530 \mathrm{~nm}$ ), Blue (450 nm), and UV (365 nm) light were used to irradiate samples. The experimental method involved turning the UV and RGB on and off at $60 \mathrm{~s}$ intervals to check whether the sensor responded. Also, the response variation was investigated by continuing the on and off process at $60 \mathrm{~s}$ intervals for a total time of approximately $980 \mathrm{~s}$. Through this, it was found that the fabricated sensor responded only to UV, with a current amount variation of around $2.19 \times 10^{-13} \mathrm{~A}$; the amount variation with respect to time was insignificant, at about $0.1 \%$.

$$
\begin{aligned}
& E_{p h}=h v=h \frac{c}{\lambda} \\
& (h=\text { Planck's constant, } c=\text { velocity of light })
\end{aligned}
$$

These results can also be verified using Eq. (1), in which 


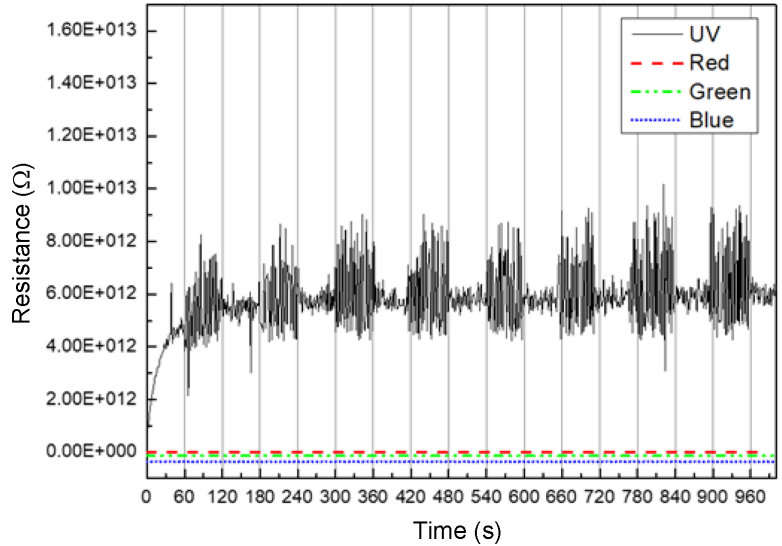

Fig. 9. Response of Ultra Violet Sensor according to R.G.B Light Source.

the energies calculated for the wavelengths of Red, Green, and Blue do not exceed approximately $3 \mathrm{eV}$.

Red, Green, and Blue, which have low energy, did not have sufficient energy to excite the electrons within the band gap, so electron movement did not occur and the sensor did not respond. On the other hand, UV (365 nm) with an energy of $3.39 \mathrm{eV}$, excited the electrons and the sensor responded. When the UV was turned on, energy was transferred, causing electron movement and current change. When the UV was turned off, there was no response because of the lack of electron movement.

\subsection{Sensor Response According to MPA Content}

The sensor response according to the MPA content was investigated; the results are shown in Fig. 10. As the MPA content increased, the amplitude and current decreased. This result is related to the Schottky diode structure: the operation of the Schottky diode is affected by defects within the band gap as well as by the dangling bond in the interface and internal defects. Taking into consideration the XRD measurement result data, it was observed that surface defects increased with increasing MPA content during the ZnS:Mn/ZnS QD fabrication; such surface defects exist in the form of additional layered defects as the shell forms, so that the electrons captured by the electron drought effect are recaptured by a different defect layer, resulting in increased resistance and degraded sensor properties. ${ }^{19-21)}$

Also, based on the XPS data, the ZnS:Mn/ZnS QD band gap results revealed that the band gap increased as the MPA content increased; Fig. 10 shows that this result has an effect on the sensor as well. UV (365 nm), which provided the energy that drove the sensor, has relatively low energy. When such low energy is used to irradiate the sample, the band gap increases and the traps within the band gaps (defect level) exist in a layered form. In the case of QDs, the electrons do not receive sufficient energy to move from the valence band to the conduction band; the resistance increases as electron movement becomes difficult due to traps between the valence band and the conduction band.

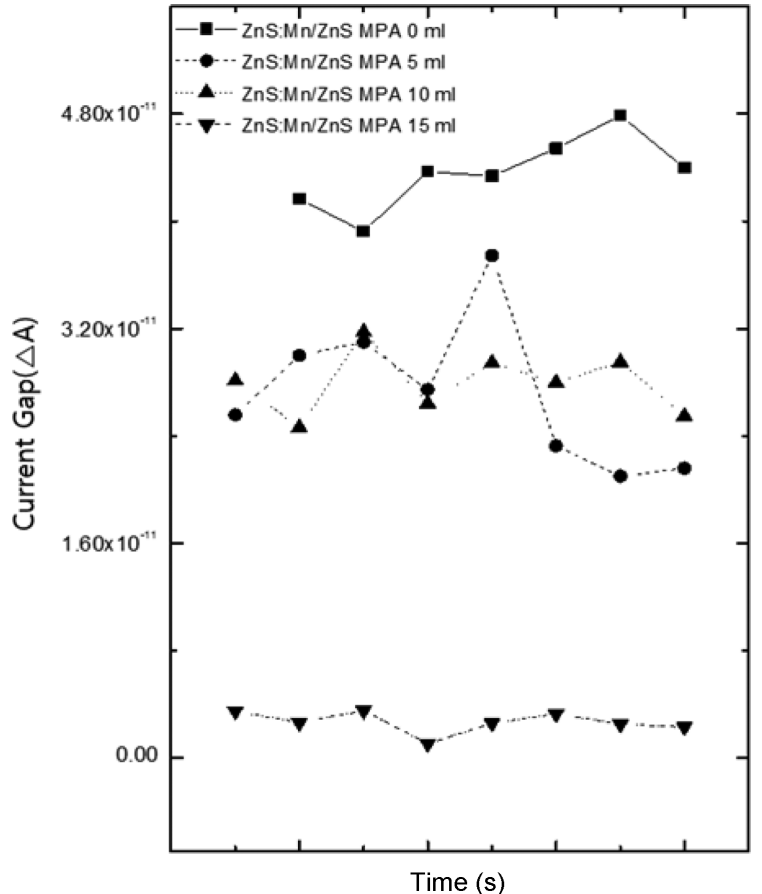

Fig. 10. Response of sensor to different amounts of MPA of $0 \mathrm{ml}, 5 \mathrm{ml}, 10 \mathrm{ml}, 15 \mathrm{ml}$.

As a result, the sensor response variation range was almost 0 and the variation with respect to time was very small at around $0.1 \%$.

Meanwhile, when the band gap is small, the layer defects produced due to MPA increase during shell formation also decreased and this allows for electron movement from the valence band to the conduction band with only small input energy. For the first $60 \mathrm{~s}$, no response was observed; however, with time, the response variation increased to about $0.8 \%$.

Thus, the ZnS:Mn/ZnS QD based sensor exhibited excellent sensor characteristics when the MPA content decreased.

\section{Conclusions}

The investigated properties of the $\mathrm{ZnS}: \mathrm{Mn}^{2+} \mathrm{ZnS}$ shell quantum dots fabricated using the room temperature solution method revealed that for $\mathrm{ZnS}: \mathrm{Mn} / \mathrm{ZnS}$, the PL peak shifted from $603 \mathrm{~nm}$ to $598 \mathrm{~nm}$ and the crystallinity decreased as the MPA content increased; however, the PL intensity increased by about $613 \%$ for the $15 \mathrm{ml}$ MPA sample, in contrast to that value of the $0 \mathrm{ml}$ MPA sample, which saw no increase. Diffraction patterns showed that the $\mathrm{ZnS}$ shell half-width increased as the MPA content increased; this led to a decrease of the crystallinity. For the $\mathrm{ZnS}$ shell, it was observed that the band gap increased as the MPA content increased.

As for photoconductive sensors, their properties improve because the pattern electrodes are closer. R.G.B testing carried out to evaluate the potential of this material for use in a UV sensor showed that the energies calculated using the 
wavelengths for R.G.B did not exceed $3 \mathrm{eV}$, while the energy for UV was about $3.39 \mathrm{eV}$. Hence, the sensor was observed to respond when the wavelength energy was greater than 3 eV. Furthermore, for the $\mathrm{ZnS}: \mathrm{Mn} / \mathrm{ZnS}$ QDs, the maximum current (A) decreased from $4.00 \times 10^{-11} \mathrm{~A}$ to $2.62 \times 10^{-12} \mathrm{~A}$ as the MPA content increased; this was deduced as being due to the increase in the surface and internal defects, leading to these defects taking the form of layer defects. This result was attributed to the variation in the band gap, calculated from the XRD diffraction pattern and XPS results.

For the $\mathrm{ZnS}: \mathrm{Mn} / \mathrm{ZnS}$ QDs, the sensor characteristics were observed to degrade as the MPA content increased.

\section{Acknowledgments}

This work was supported by Priority Research Centers Program through the National Research Foundation of Korea (NRF) funded by the Ministry of Education (NRF2017R1A6A1A03015562).

\section{REFERENCES}

1. C. J. Yoon, K. A. Cho, and S. S. Kim, "Nanomaterial Photo Sensor (in Korean)," J. KIEE., 59 [6] 19-22 (2010).

2. S. G. Kim, "A Study on the Basic Concepts and Principles of Optical Sensors (in Korean)," J. KIIEE., 20 [2] 34-41 (2006).

3. B. C. Lee and S. Y. Kim, "Optical Sensor Technology and Application (in Korean)," Magazine of the IEEK, 43 [3] 2740 (2016).

4. T. Oh, "Correlation between Oxygen Related Bonds and Defects Formation in $\mathrm{ZnO}$ Thin Films by Using X-Ray Diffraction and X-Ray Photoelectron Spectroscopy," Kor. J. Mater. Res., 23 [10] 580-85 (2013).

5. H. S. Hong, K. S. Park, C. G. Lee, B. S. Kim, L. S. Kang, and Y. H. Jin, "Present Status and Future Prospect of Quantum Dot Technology,” J. Kor. Powd. Met. Inst., 19 [6] 451-57 (2012).

6. J. Yang, J.Cao, and L. Yang, "Fabrication and Photoluminescence of $\mathrm{ZnS}: \mathrm{Mn}^{2+}$ Nanowires/ZnO Quantum Dots/ $\mathrm{SiO}_{2}$ Heterostructure," J. Appl. Phys., 108044304 (2010).

7. B. T. Luong, E. Hyeong, S. Ji, and N. Kim, "Green Synthesis of Highly UV-Orange Emitting ZnSe/ZnS:Mn/ZnS Core/Shell/Shell Nanocrystals by a Three-Step Single Flask Method," RSC Adv., 2 12132-35 (2012).

8. D. Jiang, L. Cao, W. Liu, G. Su, H. Qu, Y. Sun, and B. Dong, "Synthesis and Luminescence Properties of Core/ Shell ZnS:Mn/ZnO Nanoparticles," Nanoscale Res. Lett., 4 [1] 78-93 (2009).
9. S. Y. Cho and J. W. Song, "Display Using the CdSe/ZnS Quantum Dot," J. IEIE., 51 [8] 1851-55 (2014).

10. J. H. Heo, Applications of Mercaptoacetic Acid and Aspartic Acid Capped ZnS:Mn Nanocrystals as a Photo-Sensor and a Photo-Catalyst, pp. 1-5, in Master Thesis, Dankook University, Yongin, 2016.

11. S. Sahoo, S. K. Barik, A. P. S. Gaur, M. Correa, G. Singh, R. K. Katiyar, V. S. Puli, J. Liriano, and R. S. Katiyar, "Microwave Assisted Synthesis of ZnO Nano-Sheets and Their Application in UV-Detector," ECS J. Solid State Sci. Technol., 1 [6] 140-43 (2012).

12. J. M. Costa-Fernández, R. Pereiro, and A. Sanz-Medel, "The Use of Luminescent Quantum Dots for Optical Sensing," TrAC., 25 [3] 207-18 (2006).

13. J. H. Ahn and J. H. Kim, "Strain-Free AlGaN/GaN Nanowires for UV Sensor Applications," Korean Chem. Eng. Res., $\mathbf{5 0}$ [1] 72-5 (2012).

14. B. Dong, L. Cao, G. Su, W. Liu, H. Qu, and H. Zhai, "WaterSoluble ZnS:Mn/ZnS Core/Shell Nanoparticles Prepared by a Novel Two-Step Method," J. Alloys Compd., 492 [1-2] 363-67 (2010).

15. M. Vos, S. W. King, and B. French, "Measurement of the Band Gap by Reflection Electron Energy Loss Spectroscopy," J. Electron Spectrosc. Relat. Phenom., 212 74-80 (2016).

16. J. S. Kim and E. K. Kim, "Properties and Device Applications of Quantum Dot Molecules," J. Nat. Sci., 26 1-18 (2006).

17. G. W. Shu, W. Z. Lee, I. J. Shu, J. L. Shen, J. C. A. Lin, W. H. Chang, R. C. Ruaan, and W. C. Chou, "Photoluminescence of Colloidal CdSe/ZnS Quantum Dots Under Oxygen Atmosphere," IEEE Trans. Nanotechnol., 4 [5] 632-36 (2005).

18. P. A. G. Beerman, Synthesis and Spectroscopic Characterization of Manganese Doped Zinc Sulfide Quantum Dot Nanocrystals," pp. 15-116, in Ph.D. Thesis, Western Michigan University, Michigan, 2005.

19. J. C. Moore and C. V. Thompson, "A Phenomenological Model for the Photocurrent Transient Relaxation Observed in ZnO-Based Photodetector Devices," Sensors, 13 [8] 9921-40 (2013).

20. K. J. Choi and J. L. Lee, "Effects of Surface States and Bulk Electron Traps on Gate Leakage Current and Transconductance Dispersion in an AlGaAs/InGaAs p-HEMT," Korean J. Met. Mater., 38 [8] 1118-25 (2000).

21. Y. S. Kim, J. R. Whang, S. K. Lee, and J. S. Park, "A Model for Trap-State Density Considering Two-Type Defects in Polysilicon Thin Film Transistors," J. KIEE., 43 [11] 1922-27 (1994). 